\title{
ENTRE OS PIONEIROS DO URBANISMO NO PARANÁ
}

\section{Renato Leão Rego, Wilian da Silva Destefani, Joice Ellen de Cristo}

\section{Resumo}

Este trabalho, que é parte de uma pesquisa abrangente em andamento, trata de analisar a produção deum grupo de profissionais responsáveis por projetos urbanosimplantados no Paraná em meados do século XX. Para tanto foram consideradas sessentae três cidades novas planejadaspordezoito companhias imobiliárias envolvendo o trabalho de vinte e um profissionais, entre engenheiros e agrimensores. A partir dos dados biográficos e do currículo escolar destes projetistas, este trabalho reconstrói a noção de urbanismo materializada nos traçados originais destas cidades e, com isso, acrescenta um capítulo à narrativa da circulação de ideias de planejamento pelo interior do país.

\section{Palavras-chave:}

circulação de ideias, cidades novas planejadas, urbanismo academicista.

\section{Abstract}

This paper, which is part of a comprehensive research in progress, analyses the work of a group of professionals responsible for designing the planned new towns built in northern Paraná state in mid-twentieth century. It thus considered sixty-three new towns planned by eighteen companies that involved the expertise of twenty-one professionals, amongst surveyors and civil engineers. Regarding their biographic data as well as their academic curricula, this paper points out the notion of town planning depicted in the original town layouts and, thus, adds a chapter to the narrative of the town planning diffusion throughout Brazilian hinterland.

\section{Keywords:}

planning diffusion, planned new towns, academicist town planning. 


\section{Introdução}

É bastante conhecida a atuação das duas principais companhias de colonização no norte do estado do Paraná até a metade do século passado. A pioneira Companhia de Terras Norte do Paraná (CTNP), de capital britânico e comandada pelo escritório central sediado no coração financeiro de Londres, pautou suas atividades fundiárias em um esquema de colonização sistemática e urbanização deliberada cujo modelo não era senão uma adaptação ao contexto local e à iniciativa privada do modelo de cidade social proposto por Ebenezer Howard; com isso, pequenas cidades independentes e espaçadas regularmente, separadas por cinturão verde que protegia as nascentes vizinhase conectadas pela ferrovia, eram a base da ocupação territorial junto com o micro parcelamento da zona rural (Rego, 2009).

Com a liquidação da empresa britânica na metade dos anos 40 e a constituição de uma nova companhia de capital nacional - a Companhia Melhoramentos Norte do Paraná (CMNP), o esquema de urbanização acabou sendo reajustado; na solução dos problemas urbanos da Londres metropolitana, o esquema de Howard havia dado lugar à noção de cidades satélites, entãoconsolidada através dos subsequentes trabalhos de Raymond Unwin, Benjamin Purdom e Patrick Abercrombie, e, de modo semelhante, no norte do Paraná, o novo esquema de urbanização não deixava de refletir essa nova prática de planejamento. Com formação em engenharia civil pela Escola Politécnica de São Paulo, diretores da CMNPentão criaram no norte paranaense uma estrutura hierarquizada com quatro cidades principais, cidades menores intermédias e pequenas cidades dependentes - uma constelação de assentamentos urbanos. Em um contexto em que pesavam a estatização da ferrovia construída pelos britânicos (assim como das demais ferrovias privadas do país), a iminente canalização do investimento estatal para o rodoviarismo e a indústria automobilística, e a frequente ameaça de ocupação ilegal de uma área ainda pouco urbanizada, a CMNP permitiu que outras companhias imobiliárias também fundassem pequenos assentamentos urbanos em sua propriedade; além disso, outras empresas que buscavam o mesmo sucesso financeiro praticaram, nas imediações das terras da CMNP, um urbanismo similar (Rego e Meneguetti, 2010).

No caso da primeira companhia colonizadora, é sabido que seu escritório técnico, controlado pelos diretores londrinos, criava e implantava as novas formas urbanas. Técnicos estrangeiros formados em geodesia ou agrimensura, basicamente, respondiam pela tarefa projetual. Este é o caso dos agrimensores russosVladimir Babkov e Alexandre Razgulaeff; o projeto de Londrina, a primeira cidade fundada pelos britânicos na região,é de autoria de Razgulaeffcom significativas interferências 
feitas pelo escritório londrino da companhia (Yamaki, 2003; Rego, 2009); além deles, pode-se mencionar ainda LudovicSurjus, agrimensor francês também contratado pela CTNP, embora Surjus não pareça ter projetado cidade alguma (Batista, 2005). Mas, na verdade, apenas há registro de autoria da planta de Londrina; as demais cidades fundadas pela CTNP foram "assinadas" pelo escritório técnico da empresa.De toda sorte, estas cidades apresentam um claro padrão urbanístico ajustado a uma prática projetual inteligente: a grelha gerou formas urbanas diferenciadas, criadas a partir da adaptação do traçado à morfologia do sítio.

No caso da Companhia Melhoramentos, sabe-se que ela recorreu a Jorge de Macedo Vieira para o projeto de duas das suas cidades principais: Maringá (1945) e Cianorte (1953), que exibem a aplicação de princípios formais do ideário Garden City. A outra cidade principal (Umuarama, 1955) teve projeto elaborado pelos engenheiros Waldomiro Babkov e Manoel Mendes Mesquista, também funcionários do escritório técnico da companhia colonizadora. Entretanto, é preciso lembrar que a CMNP era dirigida por dois engenheiros civis - Gastão de Mesquita Filho e Cássio Vidigal, ambos graduados pela Escola Politécnica de São Paulo - o primeiro formado em 1919, o mesmo ano de formatura de Prestes Maia e dois anos depois da graduação de Macedo Vieira. Com relação à forma urbana, estas cidades mantiveram o padrão de traçado e prática projetual estabelecidos pela CTNP: via de regra, a grelha era adaptada ao sítio, o centro da cidade coincidia com o centro geométrico da forma urbana, onde se localizam a praça principal e os edifícios públicos significativos. 


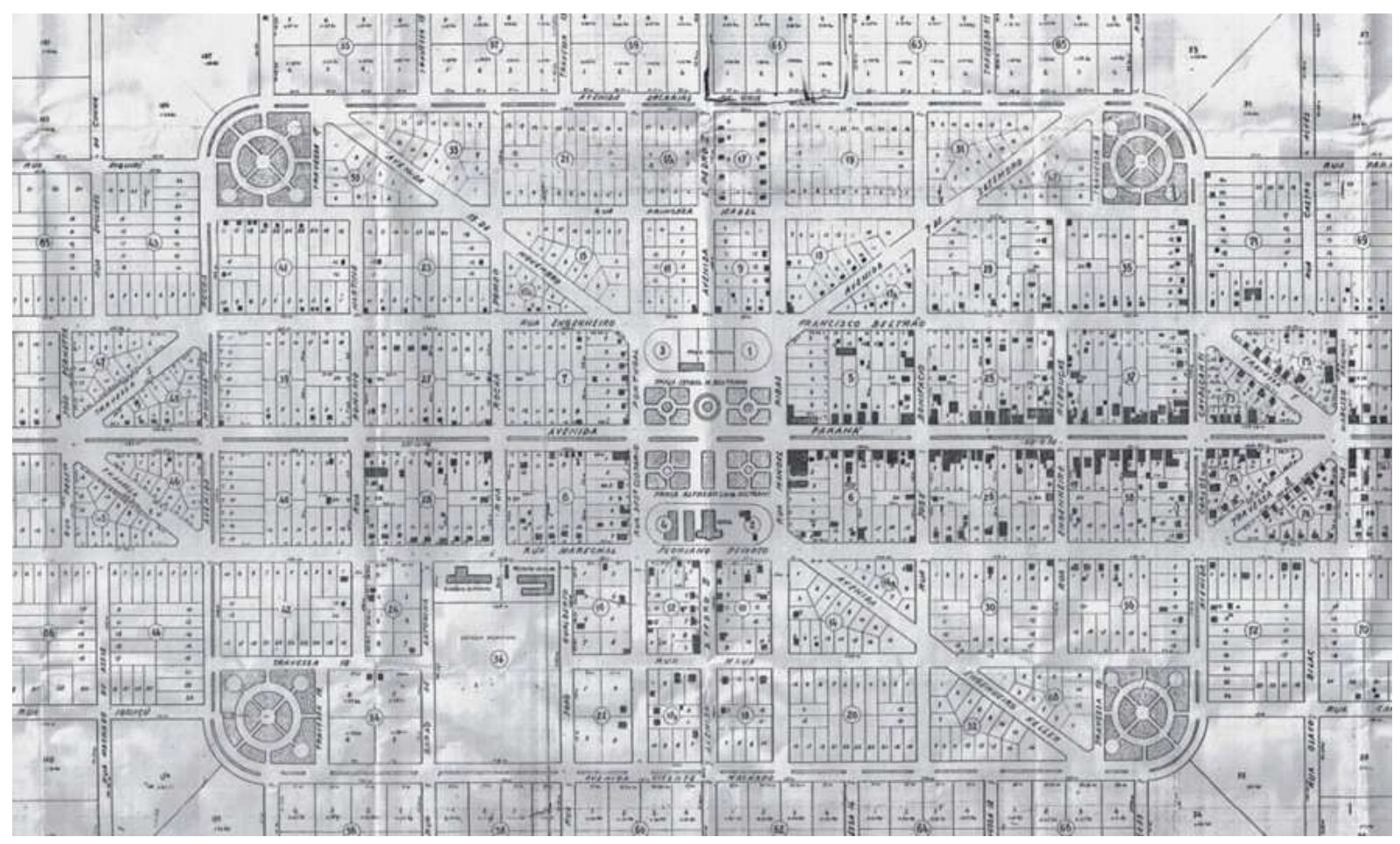

Figura 1. Traçado de Tamboara, projeto de Alexandre Beltrão (1947). Fonte: $1^{\circ}$ Cartório de Registro de Imóveis de Apucarana.

Em síntese, de um conjunto de sessenta e três cidades novas plantadas entre 1931 e 1961, nas atuais regiões norte central, noroeste e centro ocidental do estado do Paraná, trinta e oito foram fundadas pelas CTNP e CMNP a partir dos traçados elaborados pelos seus respectivos escritórios técnicos e, nos casos de Cianorte e de Maringá, por Jorge de Macedo Vieira. Mas o que dizer dasdemais cidades novas plantadas na região? Este trabalho trata exatamente de identificar os demais planejadores e projetistas que ali atuaram neste período e, mais que isso, reconhecer a ideia de urbanismo materializada nos seus projetos. Para tanto, foramconsiderados a biografia e o trabalho de dezesseis profissionais paradezesseispequenas companhias imobiliárias que, juntos, criaram vinte e cinco cidades novas planejadas.

\section{Profissionais forâneos}

Tem sido intensa a conexão entreo norte do Paraná e a metrópole paulista desde o início da colonização daquela região. Notadamente, a história do norte do Paraná começa como "um capítulo da vida paulista em território paranaense" (Müller, 1956, p.55). Mesmo pertencendo administrativamente ao estado do Paraná, ela foi considerada uma região de economia paulista (Monbeig, 1935, p.221). Toda a sua produção de café convergia para um centro articulador - técnico, financeiro e 
mercantil - a cidade de São Paulo, e depois para um único porto, Santos (Sevcenko, 1992, p.108).

Londrina, sede local da companhia colonizadora e local de passagem do todos os que buscavam terras na região, contava então com "dois aviões diários para as capitais paranaense e bandeirante" (A Pioneira, 1952), além da conexão rodoferroviária. Supreendentemente, segundo estatísticas do Departamento de Aviação Civil, entre 1958 e 1962 o aeroporto da cidade foi o terceiro do país em pousos e decolagens, ficando atrás apenas de Congonhas, em São Paulo, e do Santos Dumont, no Rio de Janeiro (Suzuki, 2003, p.60). Maringá, por sua vez, inaugurou o terminal de passageiros do aeroporto em 1953, seis anos depois da fundação da cidade, mas também já contava, havia dois anos, com voos diretos para São Paulo (Prandini, 1954).

Com uma economia pulsante e um ritmo de crescimento febril, as cidades da zona de colonização norte-paranaense eram um campo de possibilidades. Por um lado, as relações econômicas entre a metrópole a zona de colonização estimularam a "exportação" de modelos arquitetônicos e práticas de urbanismo. Nesse sentido, empresas paulistas "enviaram" ao norte do Paraná profissionais que imprimiram à cena provinciana daquelas cidades de colonização uma imagem condizente com a representatividade necessária a suas filiais, em particular as casas bancárias e as edificações levantadas pelas companhias colonizadoras (Rego, 2012). Assim foram levados ao norte do Paraná projetos de Rino Levi, Jorge de Macedo Vieira, José Augusto Bellucci - profissionais sediados em São Paulo que, mesmo à distância como foi o caso de Macedo Vieira, moldaram uma paisagem moderna no interior. 


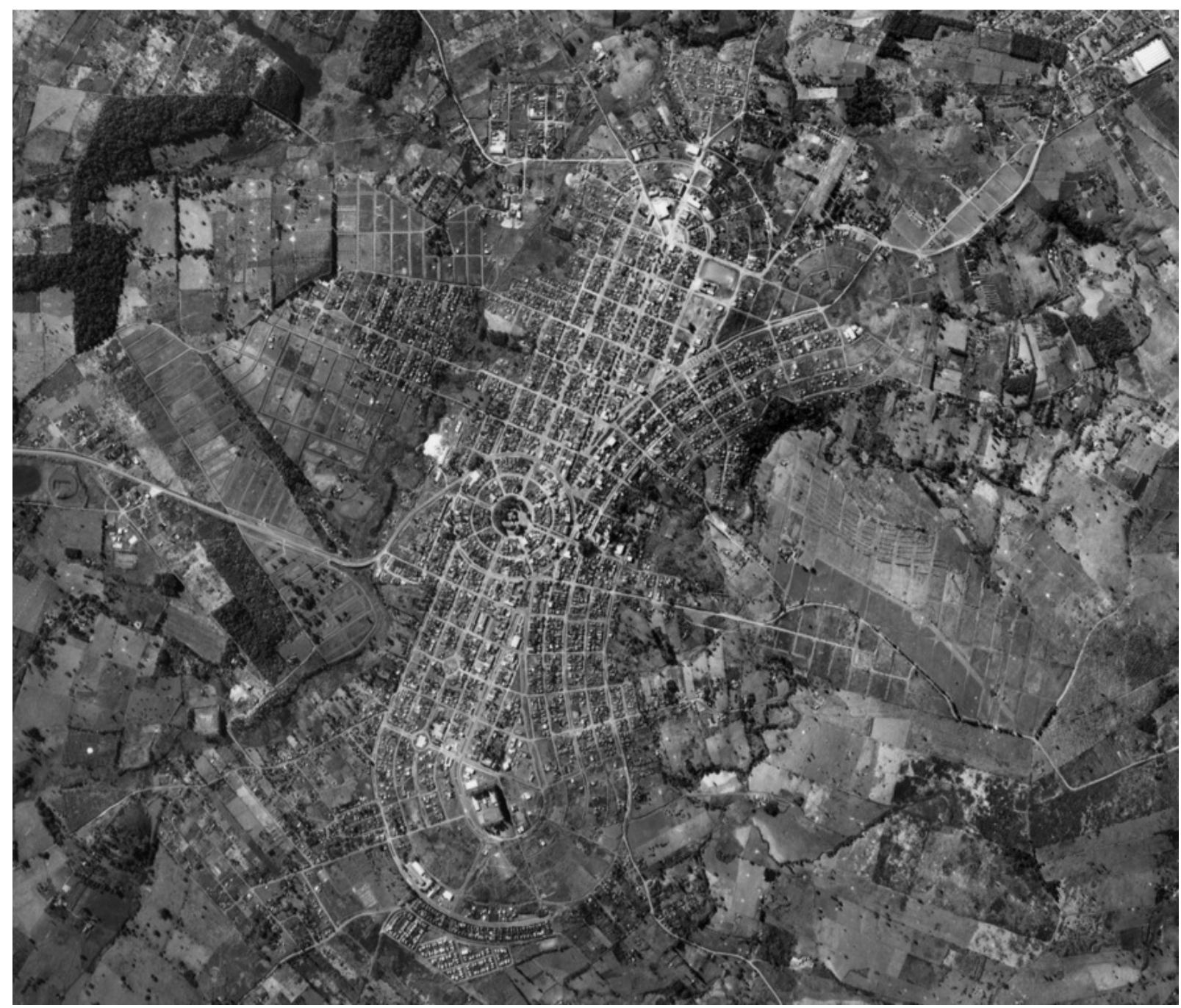

Figura 2. Foto aérea de Ivaiporã, projeto de YaroslauSessak (1953).

Fonte: Instituto de Terra, Cartografia e Geografia, 1980.

Macedo Vieira e Bellucci foram contratados pela CMNP; o primeiro para elaborar projetos urbanos e o segundo, que já tinha projetado a casa de um dos diretores da CMNP em São Paulo, deveria projetar o hotel da companhia em Maringá e acabou desenvolvendo várias obras públicas na cidade. Bellucci foi responsável pelo projeto do Aeroporto da cidade (1953), do Maringá Clube (1956), da Catedral (1957), da praça Napoleão Moreira da Silva (1957), da urbanização do Cemitério Municipal (1964) e do Paço Municipal (1967), assim como da Praça Pedro II e do Teatro, ambos de 1976, embora esses dois últimos não tenham sido executados (Verri Jr., 2001); isto significa que Bellucci projetou para a companhia colonizadora sediada em São Paulo e, em seguida, para o poder público e a Igreja.

O arquiteto Jacques Pilon projetara em 1941 a filial londrinense do Banco Noroeste do Estado de São Paulo e mais tarde, em 1960, Rino Levi elaborou o projeto da agência do Banco Sul Americano. Antes de projetar esta agência em Londrina, Rino 
Levi projetara a de Maringá (1955-59) e a de São João do Caiuá (1957-58). Neste período Phillip Lohbauer, engenheiro-arquiteto alemão sediado em São Paulo, projetou mais de quarenta edificações no Paraná, muitas delas para a Empresa de Construções Brasil que, nos anos 40, executou uma série de edifícios nas fronteiras agrícolas da época - o oeste do estado de São Paulo e o norte do Paraná (Suzuki, 2011, p.58).

Por outro lado, os anseios da elite local e a deferência cultural para com a sociedade e os costumes metropolitanos desencadearam, já no final dos anos 40, iniciativas locais para a "importação" de ideias e profissionais (Rego, 2012). Esse é o caso de arquitetos e urbanistas como Francisco Prestes Maia, Vilanova Artigas, Carlos Cascaldi, Léo Ribeiro de Moraes,Ícaro de Castro Melo e outros profissionais que, então reconhecidos em âmbito nacional, foram convidados por instituições ou pessoas da sociedade local para levarem ao interior do Paraná algo da modernidade entrevista na metrópole.

Prestes Maia, ex-prefeito de São Paulo e renomado planejador, visitou Londrina com o intuito de elaborar um 'plano urbanístico' para a principal cidade do norte paranaense (O Município, 1951a; O Município, 1951b; Yamaki, 2006, p.70). A proposta urbanística apresentada por Prestes Maia nos últimos dias de 1951 e imediatamente transformada na Lei Municipal 133/1951introduziu o zoneamento funcional, que "organiza verdadeiramente as cidades e é a maior característica de sua civilização e mentalidade, a medida mais reveladora dos seus costumes e capacidade de vida conjunta" (Maia, c.1952); instituiu a hierarquização viária e "as ideias de 'unidades residenciais' (Neighbourhood-unit), cidades-jardins, bairros-jardins, cidades lineares e outras concepções urbanísticas referentes a organização e conjuntos" (cf. Londrina. Lei Municipal 133/1951, Art. 16); determinou que os arruamentos e loteamentos atendessem "à adaptação ao terreno, e preservação dos acidentes interessantes, belezas naturais, pontos de vista" e "às melhores normas de urbanismo", o que significava "evitar, no traçado da malha urbana, irregularidades excessivas", que dessem mais a "idéia de fantasia do que de um funcionalismo racional", mas que recusassem "a rigidez excessiva" (cf. Londrina. Lei 133/1951, Art. 11 e 14); demonstrou cuidado com a paisagem e a natureza, prescrevendo a arborização urbana para conforto ambiental e embelezamento como "barato, belo e agradável complemento das cidades"; e o fez respaldado pelo "ensinamento de outras cidades" (Maia, c.1952).

Prestes Maia fora levado a Londrina pela SAL, a Sociedade Amigos de Londrina que também se encarregaria de levar para o interior Artigas e Cascaldi; esta dupla foi 
responsável por vários edifícios em Londrina, tanto públicos quanto privados; entre suas obras na cidade, contam a Rodoviária (1948-52), o Autolon (1948-51), o Cine Teatro Ouro Verde (1948-52), a Casa da Criança (1950-55), o Vestiário do Londrina Country Clube (1951), a Residência do prefeito Milton Ribeiro de Menezes (1952) e a ampliação da Santa Casa (1952-55); além desses edifícios construídos, também foram projetados o Hospital de Londrina em 1948, o Ginásio de Esportes do Londrina Country Clube e o Posto Transparaná em 1950, a sede das Oficinas Chevrolet em 1951 e o Estádio Municipal em 1953 (cf. Suzuki, 2003; Kamita, 2000); com tantos encargos em Londrina, Carlos Cascaldi acabou mudando-se para lá, onde viveu entre 1953 e 1956 - período em que ainda projetou o Aeroporto.

\begin{tabular}{|c|c|c|}
\hline Profissional & Local e data de formação & Projetos \\
\hline Eng. civil Adauto da Silva Rocha & Universidade do Paraná, 1942 & $\begin{array}{l}\text { Sta. Cruz do Monte Castelo } \\
(1951)\end{array}$ \\
\hline Eng. civil Afrânio Jonas & desconhecido & Loanda (1952) \\
\hline Eng. civil AlexandreBeltrão & Universidade do Paraná, 1946 & $\begin{array}{l}\text { Tamboara (1947) } \\
\text { Engenheiro Beltrão (1949) }\end{array}$ \\
\hline Eng. civil Américo Sato & Universidade do Paraná, 1951 & $\begin{array}{l}\text { Cidade Gaúcha (1952) } \\
\text { Cafezal do Sul (1953) }\end{array}$ \\
\hline Eng. civil Arthur Bruno Junges & Desconhecido & $\begin{array}{l}\text { Altônia (1953) } \\
\text { Pérola (1953) } \\
\text { Esperança Nova (1960) } \\
\text { S. Jorge do Patrocínio (1960) }\end{array}$ \\
\hline $\begin{array}{l}\text { Eng. civil BeneditoCláudioPassos de } \\
\text { Paula }\end{array}$ & Universidade do Paraná, 1952 & Planaltina do Paraná (1953) \\
\hline Eng. civil Dimitri Novikov & $\begin{array}{l}\text { (imigrante russo, sem } \\
\text { informação de registro } \\
\text { profissional local) }\end{array}$ & Ângulo (1949) \\
\hline Eng. civil João Maria Rocha & Universidade do Paraná, 1958 & $\begin{array}{l}\text { Arapuã (1961) } \\
\text { Ariranha do Ivaí (1961) }\end{array}$ \\
\hline Eng. civil José GantusNeto & $\begin{array}{l}\text { Escola de Engenharia } \\
\text { Mackenzie, } 1946\end{array}$ & Itaúna do Sul (1955) \\
\hline Eng. agrimensorKazutoshi Shibuya & $\begin{array}{l}\text { Escola Superior de } \\
\text { Agrimensura de Araraquara, } \\
\text { 1970* }\end{array}$ & $\begin{array}{l}\text { Icaraíma (1951) } \\
\text { Ivaté }(1958)\end{array}$ \\
\hline Eng. civil KleperGonçalvesPalhano & desconhecido & Paranapoema (1952) \\
\hline Eng. civil MosartOubert & desconhecido & Alto Paraná (1949) \\
\hline Eng. civil Odilon Borges de Carvalho & desconhecido & Barbosa Ferraz (1948) \\
\hline Eng. civil OthonMader & desconhecido & $\begin{array}{l}\text { Rio Bom (1942) } \\
\text { Borrazópolis (1948) }\end{array}$ \\
\hline Eng. agrônomo Wilson Dantas & desconhecido & Guairaçá (1946) \\
\hline Eng. civil Yaroslau Sessak & Universidade do Paraná, 1948 & $\begin{array}{l}\text { Paranacity (1949) } \\
\text { Ivaiporã (1953) }\end{array}$ \\
\hline
\end{tabular}

Tabela 1. Lista dos profissionais responsáveis pelo projeto de 25 cidades novas paranaenses. * note-se a data de graduação posterior à elaboração dos projetos urbanos. 
Do mesmo modo, Ribeiro de Moraes foi responsável pelo projeto do Shangri-lá, um "aristocrático bairro residencial" criado por uma imobiliária local no começo dos anos 50 a partir do modelo gardensuburb e possibilitado pela nova legislação urbana criada por Prestes Maia. E Ícaro de Castro Mello foi contratado pela Sociedade Evangélica Beneficente em 1955 para a elaboração do projeto de um novo hospital para Londrina, uma edificação com $6.000 \mathrm{~m}^{2}$ e 150 leitos; Castro Melo, já renomado desportista e arquiteto responsável pelo projeto do Ginásio do Ibirapuera (1952), também foi convidado a projetar o Country Clube de Maringá (1954-58).

Entretanto - e ao contrário do que se supunha - o traçado das cidades novas se deve tanto a profissionais paulistas ou egressos de escolas paulistas quanto àqueles oriundos da Escola de Engenharia de Curitiba. Com efeito, os vinte e cinco projetos urbanos analisados foram assinados por um grupo de dezesseis profissionais cuja formação predominante é a de engenheiro civil, ainda que entre eles se encontre um engenheiro agrimensor e um agrônomo. Dentre os engenheiros cuja escola de formação pôde ser identificada (até a preparação deste texto), conta-se um egresso da Escola de Engenharia do Mackenzie e seis da Universidade do Paraná, graduados entre os anos 1942 e 1958 (Tabela 1). O trabalho deste grupo de profissionais merece atenção.

\section{Urbanismo academicista}

De acordo com Pinheiro (2009), não foi antes da segunda metade do século XX que o urbanismo academicista acabou sendo substituído pela 'cidade funcional'. Nos anos 40 ainda se nota a tradição Beaux-Arts nos projetos urbanos propostos para as capitais sul-americanas; o pensamento academicista, através da presença de arquitetos e urbanistas estrangeiros, continua prevalecendo. 


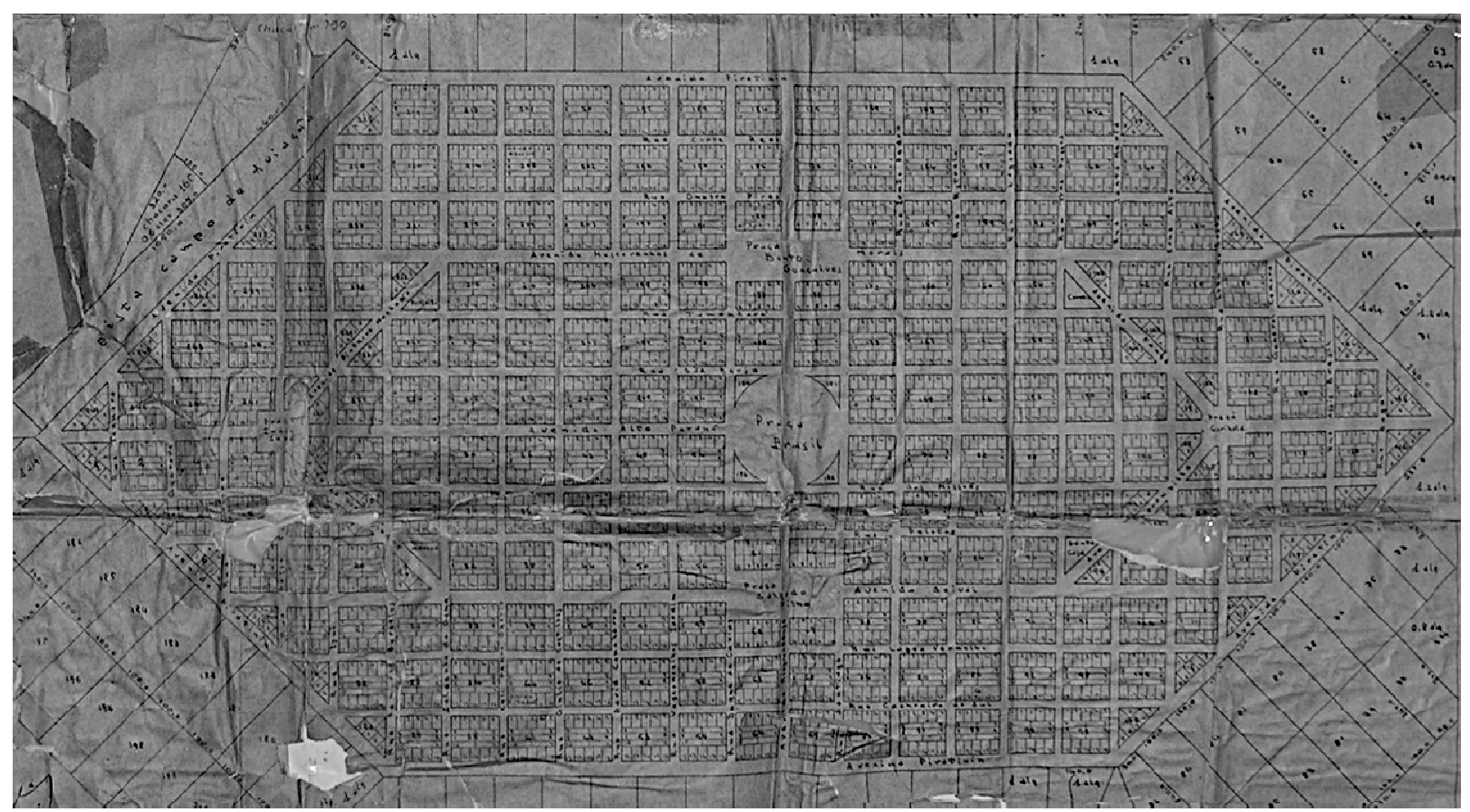

Figura 3. Projeto de Cidade Gaúcha, Américo Sato, 1952.

Fonte: $1^{\circ}$ Cartório de Registro de Imóveis de Campo Mourão.

Com efeito, antes da supremacia do pensamento racionalista, o Grand Urbanisme europeu era a grande referência para novos planos urbanísticos. O Novo Mundo então olhava para a Europa em busca de exemplos para a modernização das suas cidades e o que certamente atraía o olhar externo era a tradição europeia de ordenamento urbano em 'grande estilo', aquela que enfatizava longas vias retas culminando em vistas espetaculares, praças formais, parques ricamente elaborados, a ordem geométrica e a habilidade de relacionar todos estes elementos em uma unidade coerente.O Grande Urbanismo, do qual a Paris de Haussmann era um dos produtos mais reluzentes, acabou motivando o trabalho de profissionais dos dois lados do Atlântico: seja o movimento norte-americano City Beautiful - que tem seu ponto alto no Plano de Chicago; seja a mobilização inglesa em torno do Civic Design ou das Cidades Jardins. A composição de grandes traçados e a disposição de conjuntos monumentais refletiam a preocupação com aspectos funcionais sem abandonar, porém, as intenções de embelezamento do século XIX e as composições de natureza Beaux-Arts (Rego, 2010).

Nesse período, as expressões 'arte urbana', 'arte cívica' e 'arte pública' eram utilizadas para designar uma certa atuação na cidade e um campo do conhecimento que unia a composição estética à otimização funcional. Desse modo, alcançava-sea almejada beleza urbana com padrões de desenho e de planejamento que valorizavam a arte, a arquitetura e seus princípios, e aplicavam o olhar do arquiteto à escala 
urbana, enfatizando opapel das relações entre um edifício e seu entorno, das cenográficas vistas urbanas a serem criadas e do agrupamentode edificações em conjuntos harmônicos, com hierarquia e unidade monumental.

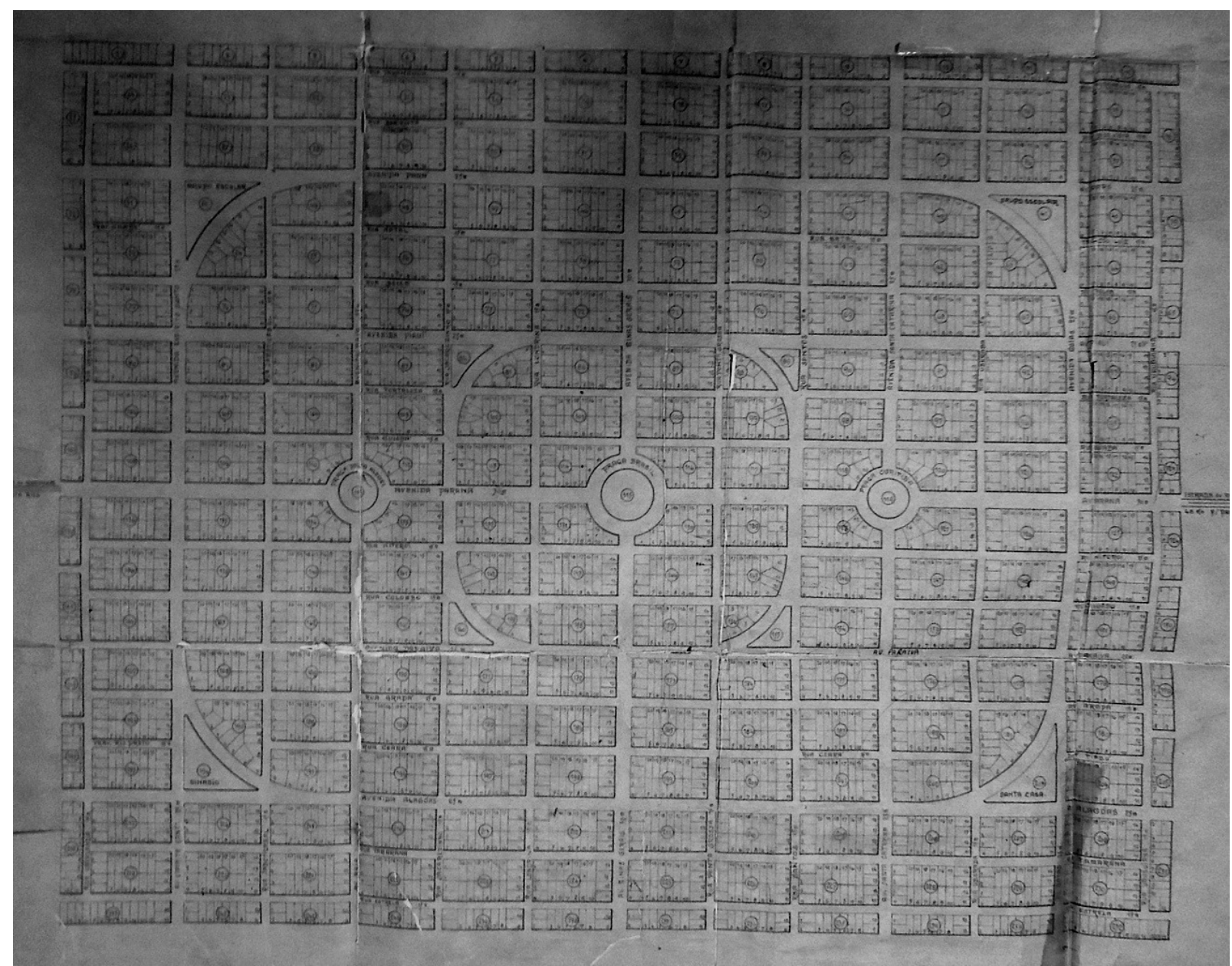

Figura 4. Projeto de Planaltina do Paraná, BeneditoCláudioPassos de Paula (1953). Fonte: $1^{\circ}$ Cartório de Registro de Imóveis de Campo Mourão.

Paralelamente, a produção acadêmica das escolas de engenharia de São Paulo e Paraná exibia exercícios projetuais de estilo Art Déco (Ficher, 2005; Dudeque, 2001).Mais especificamente, pode-se notar neste período que a paisagem curitibana era predominantemente marcada por edificaçõesprojetadas neste estilo. Nas duas Grandes Exposições de Curitiba, realizadas em 1942 e em 1943, vários pavilhões exibiam este estiloque, então,serviu às aspirações locais de afirmação urbana perante os próprios cidadãos e o resto do país. As 'linhas modernas e severas' da arquitetura alinhada com princípios perretianos que associavam herança acadêmica, rígida composição clássica, geometria simplificada e tecnologia, acabaram indicadas para quase tudo que se construía. 
Curitiba contava então apenas com o curso de engenharia para formação de profissionais projetistas e planejadores e os engenheiros-arquitetos seguiam aprendendo arquitetura por meio de esquemas acadêmicos de composição; e aí estudava-se também o 'traçado das cidades' - um componente curricular bastante frequente nos históricos escolares analisados. Havia alguma manifestação da arquitetura funcional na cidade - como a publicação local de um texto de Oscar Niemeyer em 1946 ou a execução de alguns projetos de João Batista Vilanova Artigas entre 1945 e 1953 - mas quem quisesse saber da 'nova arquitetura' "teria que se arriscar para além do que a imprensa publicava e o curso de engenharia oferecia" (Dudeque, 2001, p.135).

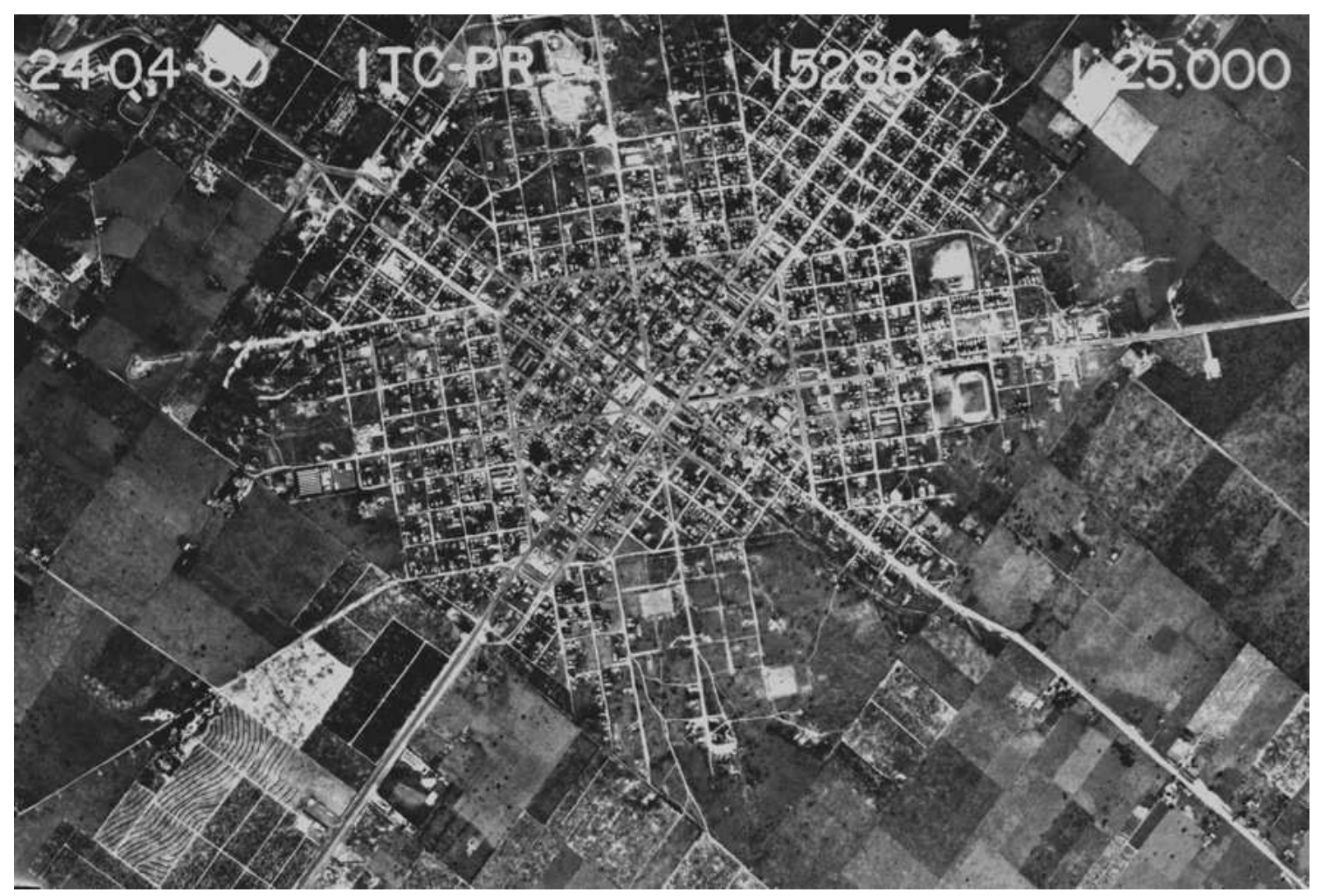

Figura 5. Foto aérea de Loanda, projeto de Afrânio Jonas, 1952.

Fonte: Instituto de Terra, Cartografia e Geografia, 1980.

Quanto ao urbanismo, o academicismo de Alfred Donat Agache era a referência curitibana por excelência. Em 1943 o arquiteto francês passou quatro meses em Curitiba a fim de desenvolver um plano que culminou com o projeto Beaux-Arts do centro cívico - originalmente um arranjo formal de edificações neoclássicas que emolduraria a praça no final de uma perspectiva grandiosa, arrematada pelo palácio do governo. Assim, vista, formalidade e conjunto eram a norma de composição. 
Interessa aqui saber que Agache contara com um assessor durante sua estada em Curitiba. Lolô Cornelsen, que viria a ser um arquiteto de renome internacional, era calouro do curso de engenharia da Universidade do Paraná e estagiário na Prefeitura Municipal e acompanhou Agache durante seus trabalhos na cidade; Cornelsen era aluno da mesma turma do futuro engenheiro Alexandre Beltrão, que projetaria um par de cidades no norte do estado; Cornelsen chegou a ser contratado como professor para a sua própria turma na disciplina artística 'Construção dos edifícios: arquitetura', dado seu 'notório saber discente'.

Nesse sentido, não se estranha a forte presença de traçados de natureza academicista entre os projetos das cidades novas do norteparanaense. Aí notam-se composições que evidenciam formas fechadas com um centro destacado, muitas vezes conformado como centro cívico, a convergência de vias diagonais diante de praças estrategicamente posicionadas no tecido urbano e o arranjo de edificações, sempre atendendo à norma academicistade vista, formalidade e conjunto. Simetria é outro elemento recorrente que pesa no apelo estético destas composições.

Assim, o urbanismo se mostrava intensamente arquitetônico. Tal como lições tomadas do City Beautiful e do Civic Design- movimentos filiados à estética BeauxArts, nota-se ali também que o urbanismo tratava de fazer pela cidade o que um arquiteto fazia por uma casa (NETTLEFOLD, 1908, p.56). Foi nesse sentido que o civic design foi entendido como a arte da arquitetura aplicada à construção da cidade (ADAMS, 1932, p.2), ou a continuação da arquitetura em uma dimensão maior (HOLFORD, 1949, p.12). O civic design era, portanto, uma extensão da esfera de influência do arquiteto, tal como aparece na obra de Werner Hegemann e ElberPeets, uma espécie de manual da arte cívica para arquitetos (MORLEY, 2008, p.11). Com efeito, se alcançava a beleza urbana com padrões de desenho e de planejamento que valorizavam a arte, a arquitetura e seus princípios, e aplicavam o olhar do arquiteto em vários contextos espaciais (MORLEY, 2008, p.56 e 61; Rego, 2010).

\section{Conclusões}

Analisando o projeto de vinte e cinco cidades novas planejadas no estado do Paraná - em especial os traçados de Loanda, Planaltina do Paraná, Cidade Gaúcha, Ivaiporã e Tamboara, todos elaborados por engenheiros graduados em Curitiba na metade do século XX-, este trabalho observou a materialização de um urbanismo de natureza academicista, ligado à ideia de 'arte cívica' e bastante próximo da estética Beaux-Arts. Tais cidades, fundadas por empresas privadas de especulação fundiária, apresentam traçados que extrapolam a aplicação direta do grid como estratégia 
projetual de novos assentamentos urbanos em zona de colonização. O arranjo dos elementos urbanos (vias, quadras, espaços livres e edificações, tratados em conjunto) demonstra um forte apelo artístico, em particular no tratamento dado à formalização dos centros urbanos. Respaldados pela tradição do Grande Urbanismo, atualizada no século XX por movimentos como o City Beautiful e o Civic Design, estes traçados refletem as discussões acadêmicas do período, ainda distantes da arquitetura racionalista e do urbanismo da cidade funcional que prevaleceram nas décadas seguintes.

A observação destas práticas no projeto das cidades novas planejadas no norte do Paraná contribui para a compreensão da difusão do urbanismo e para a construção da sua história no interior país.

\section{Referências}

Adams, T. (1932) Recent advances in town planning. Londres: J \& A Churchill. A Pioneira (1952) N.11, julho/agosto.

Batista, R. de B. (2005) LudovicSurjus:história, histórias. Londrina: Atrito Art. Dudeque, I. T. (2001) Espirais de madeira. Uma história da arquitetura de Curitiba. São Paulo: Nobel.

Ficher, S. (2005) Os arquitetos da Poli: ensino e profissão em São Paulo. São Paulo: EDUSP.

Holford, W. (1949) Civic design: an enquiry into the design and nature of town planning.Londres: H. K. Lewis.

Kamita, J. M. (2000) Vilanova Artigas. São Paulo: Cosac \&Naify.

Lei Municipal 133/1951. Publicada no jornal O Município, em 27.12.1951. P.4 e 5.

Maia, F. P. (c.1952) Manuscrito. Documento arquivado no Museu Histórico de Londrina.

Monbeig, P. (1935) A zona pioneira do Norte-Paraná, Revista Geografiav.1, n.1. P.221-238.

Morley, I. (2008) British provincial civic design and the building of lateVictorian and Edwardian cities, 1880-1914. Lewiston: The Edwin Mellen Press. Nettlefold, J. (1908) Practical housing. Letchworth: Garden City Press.

O Município. (1951) Edição $n^{\circ}$. 31, de 19/04/1951.

O Município. (1951)Edição n. 32, de 26/04/1951.

Pinheiro, E. P. (2009) Circulação de ideias e academicismo: os projetos urbanos para as capitais do Cone Sul, entre 1920 e 1940. In: Gomes, M. A. A. de F. 
(Org.). Urbanismo na América do Sul: circulação de ideias e constituição do campo, 1920-1960. Salvador: EDUFBA. P.119-148.

Prandini, N. (1954) Aspectos da geografia urbana de Londrina, Anais da Associação dos Geógrafos Brasileiros, n.6, t.1, 1951-1952. São Paulo: AGB. In Fresca, T. M. e Carvalho, M. S. (2007) Geografia e norte do Paraná: um resgate histórico. Londrina: Humanidades. P.87-113.

Rego, R.L. (2012) Importing planning ideas, mirroring progress: the hinterland and the metropolis in mid-twentieth-century Brazil, Planning Perspectives, v.27, n.4. P.625-634.

Rego, R. L. (2009) As cidades plantadas: os britânicos e a construção da paisagem do norte do Paraná. Londrina: Humanidades.

Rego, R. L. (2010) Ideias viajantes: o centro cívico e a cidade como obra de arte - do citybeautiful ao coração de Maringá, XI Seminário de História da Cidade e do Urbanismo, Anais. Vitória: UFES.

Rego, R. L. e Meneguetti, K. S. (2010) Plantedtownsand territorial organization: themorphologyof a settlementprocess in Brazil, Urbanmorphology, v.14, n.2. P.101-9.

Sevcenko, N. (1992) Orfeu extático na metrópole: São Paulo, sociedade e cultura nos frementes anos 20. São Paulo: Companhia das Letras.

Suzuki, J. (2003)Artigas e Cascaldi: arquitetura em Londrina. Cotia: Ateliê Editorial.

Suzuki, J. (2011) Idealizações de modernidade. Arquitetura dos edifícios verticais em Londrina, 1949-1969. Londrina: Kan.

Verri Jr., A. (2001) A obra de José Augusto Bellucci em Maringá. Dissertação de mestrado. São Paulo: FAU/USP.

Yamaki, H. (2003) Iconografia Iondrinense. Londrina: Humanidades.

Yamaki, H. (2006) Labirinto da memória. Paisagens de Londrina. Londrina: Humanidades. 